\title{
REPLY TO OPPENHEIMER AND PRESTON
}

\author{
STEVEN RUGGLES
}

am honored to have my essay discussed at such length by two of the most eminent scholars in the field. Because of space constraints, I will not attempt to respond to all of their points, but instead will focus on the most serious criticisms. Many of the issues raised by Preston and Oppenheimer are quite technical, and I will address them in due course. Let me begin, though, by addressing a more fundamental issue: my theoretical perspective on marital dissolution. My position seems to have been misunderstood, no doubt because my theoretical discussion was too cursory and noncommittal.

\section{THEORETICAL ISSUES}

Oppenheimer objects to my generalization that there is a virtually universal consensus among scholars that the long-run rise of separation and divorce was related to the rise of female labor-force participation. I meant only to point out that nearly every scholar who has written on the topic-regardless of their political orientation-has cited the importance of rising women's employment. I agree entirely with Oppenheimer's (1994) summary:

Not all researchers subscribe to Becker's or Durkheim's emphasis on the role of specialization per se in providing the gain to marriage and the ensuing reductions in such a gain once women's employment increases. Nevertheless, an economic independence argument of one sort or another whether it be expressed in the terminology of exchange theory or some other perspective such as feminism, has had wide appeal since it can easily be incorporated into extremely diverse theoretical and ideological positions. Even where scholars do not espouse a particular position themselves, the independence hypothesis plays a prominent role in their discussions of the major determinants of marriage behavior. In sum, married women's rising employment is increasingly seen as the single most critical factor transforming the family system of American society.... (p. 296)

As I noted, Oppenheimer is the main dissenter to the consensus; she views the scholarly emphasis on married women's work as "theoretically and empirically unwarranted."

Part of the misunderstanding, I think, results from my failure to draw a clear distinction between the interdependence theories of marriage advocated by Durkheim and Becker versus the economic-opportunity hypothesis widely cited by feminist scholars. Although both interpretations stress the influence of rising female labor-force participation on marital instability, the proposed mechanisms are different. Durkheim and Becker argue that divorce and separation rise because the overall benefits derived from marriage diminish when both spouses work. Many feminist scholars, by contrast, argue that rising opportunity for women allows increasing numbers to escape bad marriages. The interdependence theory applies to the desirability of getting married as well as to marital disruptions, whereas the economic-opportunity interpretation is mainly concerned with marital disruptions. Moreover, the key factor behind marital instability for the interdependence theory is work experience of wives at the individual level; by contrast, for the opportunity hypothesis, work experience is less important than the availability of work. On the whole, I find the economic-opportunity interpretation more persuasive than the interdependence hypothesis. ${ }^{1}$ Oppenheimer refers to both the opportunity and interdependence hypotheses as the "independence hypothesis."

I did not mean to suggest that just because the interdependence and economic opportunity hypotheses are widely cited that they have been proven. I agree entirely with Oppenheimer that just because a theory is widely credited, that does not mean that we should accept it without evidence. As I point out, there has been essentially no quantitative research on the long-run effects of rising women's employment on the frequency of divorce and separation. Indeed, I undertook this analysis because I wanted to test the theory against the evidence.

Like Oppenheimer, I think that divorces and separations ordinarily occur because of dissatisfaction with particular marriages rather than dissatisfaction with the institution of marriage. This cannot, however, help us to explain the long secular rise in marital instability over the past century. I see no reason to believe that dissatisfaction with particular marriages would have been any less in the past than today. If anything, I suspect that people were more dissatisfied with their marriages in the past than they are now, because in the past people could not easily terminate bad marriages.

In the nineteenth century, people were inhibited from ending bad marriages by a variety of constraints that have diminished markedly. Legal divorces were difficult to obtain. There was a strong social stigma associated with marital dis-

1. I do not, as Oppenheimer implies, subscribe to Becker's (1981) interpretation. As I have explained elsewhere (Ruggles 1987:16-25), I find Becker's theory of marriage highly implausible. I do not interpret the increase in the percentage separated or divorced as an indication that "people are rejecting marriage as an institution" (p.469). Nor do I "view marital breakups as indicative of a decline in the gain to marriage per se" (p. 470). Although it is possible that some Americans are increasingly rejecting marriage as an institution, I doubt that this has made a substantial contribution to the rise of divorce or separation. 
solution. And, not least, marital dissolution was simply not economically feasible for most women. As Oppenheimer points out, even today women's economic well-being usually declines after a marital disruption. In the nineteenth century, when married women in most places were excluded from employment outside the home, the decline in economic wellbeing after marital disruption was even greater, and abandonment often reduced women and their children below the level of subsistence. It seems plausible that rising employment of women during the past century reduced the economic necessity for women to remain in bad marriages and thus contributed significantly to the rise of divorce and separation.

In her stimulating and important essay on the issue, Oppenheimer (1994) argues that the rise of women's employment is not the source of the rise in marital instability. Rather, she maintains, the main source of rising divorce and separation has been declining economic opportunity for males. My analysis supports Oppenheimer's stress on the importance of opportunity for men: I find that divorce and separation are considerably more sensitive to men's economic positions than to women's. Throughout the past century, low economic opportunity and employment levels for men have been powerfully linked to high probabilities of divorce and separation. In virtually every census year, the regression coefficients for opportunity and participation for men are greater than the comparable measures for women. ${ }^{2}$ Thus, a $1 \%$ decline in economic opportunity for men consistently had a greater impact on divorce and separation than did a $1 \%$ rise in opportunity for women.

The only problem with Oppenheimer's hypothesis is that for most of the century opportunity for men was increasing, not declining. Regardless of the measure used, the economic circumstances of men improved dramatically from 1880 to 1973, with only a brief interruption during the Depression. Earnings have deteriorated for the bottom quartile of men since 1973, but this change is not nearly of sufficient magnitude to cancel out the effects of earlier improvements in opportunity for men. The incidence of divorce and separation leveled off after 1980. Thus, there have been only two comparatively brief periods during which declining opportunity for men accompanied rising marital instability: 1930-1936 and 1973-1980. Declining opportunity for men no doubt contributed significantly to the rapid rise of divorce and separation during the 1930s and the 1970s, but it cannot credibly be viewed as the main source of the century-long rise of divorce and separation.

Oppenheimer (1994) provides a needed corrective to the scholarly neglect of the role economic opportunity for men plays in marital instability. For those near the bottom of the economic hierarchy during the past two decades, declining opportunity for men was doubtless a major source of rising marital instability. My essay has a very different focus than Oppenheimer's: I am looking at the entire population over

2. The sole exceptions are for participation in 1880 and for opportunity in 1940. In both cases, the magnitude of the coefficients for men resembles the magnitude of the coefficients for women. the very long run. From that perspective, it is clear that the net effect of changes in economic opportunity for males over the past century was to diminish the odds of marital disruption, not to increase them.

Finally, I want to make it clear that I do not regard the rise of women's employment as socially destructive. On the contrary, I think it has had positive consequences that go far beyond allowing women an escape from bad marriages: The growth of women's economic power has contributed to the decline of patriarchal authority and the creation of a more egalitarian society. ${ }^{3}$

\section{METHODOLOGICAL ISSUES}

Beyond these theoretical and conceptual issues, Oppenheimer and Preston raise a variety of technical and methodological concerns. Both express reservations about my dependent variable, which is the probability of being separated or divorced among persons who are married, separated, or divorced. The problem, as Oppenheimer puts it, is that this is a measure of prevalence rather than incidence; that is, I assess the likelihood of being separated or divorced at the time of the census rather than the likelihood of becoming separated or divorced within a given period of time. Unlike conventional measures of marital instability based on vital statistics or longitudinal data, the prevalence measure is affected by remarriage as well as by separation and divorce.

Oppenheimer objects to the prevalence measure because she thinks that remarriage operates differently from divorce and separation. In particular, Oppenheimer points to the considerable state-to-state variation in divorce laws. She argues that states with the most restrictive grounds for divorce would paradoxically have the highest proportion separated or divorced at a given census because the separated people would be unable to obtain a divorce and thus could not remarry. A quick analysis of the relative frequency of separated and divorced persons by state suggests that this mechanism had little effect on the overall prevalence of divorce and separation. In all census years, there was a positive correlation across states between the proportion divorced and the proportion separated, not an inverse correlation as Oppenheimer's hypothesis would predict.

I argue that both the interdependence and the economicopportunity hypotheses should apply to remarriage as well as to divorce and separation. If remarriage varied "for reasons that have little to do with the hypotheses under investigation and they are not controlled for in the models," as Oppenheimer maintains (p. 468), then we might expect the models to fit poorly and to explain little variation across time. In fact, the relationships between the employment measures and the prevalence measure of divorce and separation-which includes remarriage - are remarkably powerful and account for more than $100 \%$ of the rise in the prevalence

3. Of course, there have been short-run adverse consequences to this social transformation, ranging from gender-role stress among women and men to inadequate affordable childcare. But these problems, I think, are transitory. 
of divorce and separation between 1880 and 1990. This is strong evidence that the dependent variable is not corrupted by remarriage. Either the hypotheses do in fact apply to remarriage as well as to divorce and separation, or for some other reason remarriage happens to behave much like divorce and separation.

In my conclusion, I mention that a preliminary analysis of the probability of being ever-married among young persons yields weaker results than the analysis of the combination of divorce, separation, and remarriage. Both Preston and Oppenheimer express surprise at this finding and suggest that the theories should apply equally to marriage formation and marital dissolution. Without more thorough analysis, I hesitate to impute much significance to this result. But if women's employment opportunities influence separation and divorce mainly by providing an escape route for women in bad marriages, they might not have a great effect on the frequency of first marriages. Thus, perhaps the economic-opportunity hypothesis is more important than the interdependence hypothesis.

Oppenheimer further suggests that remarriages ought to operate like first marriages, but it seems to me that the two differ. Presumably, divorced people in all periods had experienced bad marriages. These people might be more skeptical of marriage than is the never-married population. If divorced women had the wherewithal to avoid remarriage they might well do so, even if economic opportunity for women had only a modest impact on the probability of first marriage.

Preston suggests that the prevalence measure of marital instability is affected not only by remarriage, but also by age at marriage, widowhood, and cohabitation. Age at marriage, Preston argues, is important because the risk of divorce cumulates over the lifetime of a marriage, so those who marry earlier are at greater risk of experiencing a divorce at a particular age. Thus, Preston thinks that the prevalence measure of separation and divorce is biased upward in periods with early marriage and downward in periods with late marriage. I do not think this is correct, except to the extent that divorces occur before age 20 (the lower limit of age I consider). In periods when marriage occurs early, the denominator of the prevalence measure (the total number of persons married, separated, or divorced) will increase in exact proportion to the increased person-years of exposure to separation or divorce. Age at marriage is still important, however, simply because persons who marry early have a higher agespecific risk of separation or divorce. But this potential intervening factor is not peculiar to the prevalence measure of marital instability; it has an equal effect on conventional incidence measures.

The widowhood issue is similar. Preston argues that widows should be included in the denominator because their years spent in a nondisrupted union should count to determine the risk of separation or divorce. In fact, however, the prevalence measure I use does count the marital experience of widowed persons prior to their widowhood. The denominator includes all persons married at the time of the census; many of these, of course, are future widows and widowers. Thus, the prevalence measure fully accounts for the personyears of risk of persons who will ultimately become widowed. I do not follow the reasoning behind Preston's view that changes in cohabitation would bias the prevalence measure of divorce and separation, except perhaps by affecting the incidence of remarriage.

Preston suggests that I try including the remarried population in the disrupted group in 1910, 1940, 1970, and 1980, when information on remarriage is available. Unfortunately, the formerly widowed population can be identified only in 1970 and 1980, and in the earlier years the great bulk of the remarried population ended their first marriages by widowhood, not divorce. In 1970 and 1980, including the the formerly divorced population has little effect on the analysis.

Both Oppenheimer and Preston express reservations about my measure of economic opportunity. Any single measure of economic opportunity provides only a partial view, but it is hard to incorporate multiple measures because multicollinearity becomes a problem. Moreover, the range of possible measures is limited because occupation is the only indicator of economic status available for the entire period covered by the analysis.

I measure economic opportunity as the percentage of the local workforce engaged in occupations with median earnings under $\$ 2,200$ in 1950 . In other words, the measure represents the percentage of the work force with bad jobs. This is, of course, only one dimension of economic opportunity and it focuses on those at the bottom of the economic hierarchy. I adopted this measure partly because I wanted to address Oppenheimer's hypothesis that declining opportunity for low-status men has contributed to rising marital instability. The measure adequately captures the recent pressures on opportunity for men-the age-standardized percentage of whites with bad jobs according to this definition rose $28.2 \%$ from 1970 to 1990 . Contrary to Oppenheimer's implication, this is a significantly greater increase than occurs for the comparable measure based on real income rather than occupation. The age-standardized percentage of white men earning annual wages less than the equivalent of $\$ 2,200$ in 1950 dollars rose from 23.7 in 1970 to 27.7 in 1990, an increase of only $16.9 \% .{ }^{4}$ Thus, I am skeptical of Oppenheimer's view that my use of occupation rather than income greatly understates the real decline in opportunity for men since 1970 .

Oppenheimer also argues that I underestimate the recent decline in economic opportunities for men because my measures are based on men aged 20-59, rather than the younger age group 20-39 that I use for the analysis. I broadened the age range for the contextual variables in order to obtain sufficient cases in each district I examined. (Although the analysis as a whole involved tabulation of information on some

4. By contrast, in the earlier period from 1940 to 1970 , the age-standardized percentage of white males earning under $\$ 2,200$ in 1950 dollars dropped from 70.7 to 27.7 , while the comparable occupation-based measure dropped only from 23.1 to 11.7 . Thus, in the earlier period, the occupation measure understates the change in real income, whereas in the later period it does not. 
30 million individuals, in the early census years there are barely enough cases to calculate reasonably precise districtlevel estimates.) But Oppenheimer's point is well taken: In 1970, men aged 20-39 had slightly better jobs than those aged 40-59, and by 1990 that pattern had reversed. If I had limited the occupation measure to the younger group, the percentage of men with bad jobs would have gone up about 4.6 percentage points rather than 3.3 percentage points during that period. The resulting predicted effect of opportunity for men on separation and divorce between 1970 and 1990 would then rise by about 0.5 percentage points, all else being equal. This is a modest adjustment, but it does suggest that the predicted effects shown in Table 4 for low male opportunity from 1970 to 1990 may be a bit low.

Preston has a different concern: He feels that the economic opportunity measure is flawed because it does not capture the improvements from 1970 to 1990 in the economic opportunity of women, which mainly occurred in the top half of the income distribution. This is a reasonable point because the opportunity measure focuses on the bottom of the income distribution. The regression results show minimal significant effects for the female opportunity variable. It may be that the effect of female opportunity for recent census years would be greater if one used a measure focusing on the top half of the distribution. For the period before 1970, however, opportunity for women was so uniformly poor that it is unlikely that any measure would yield highly significant results.

Oppenheimer argues that the measures of economic participation and opportunity for men are endogenous because they are based on the married-spouse present population. I believe she is incorrect. She presents no plausible mechanism whereby the prevalence of divorce and separation could influence the labor-force participation of married men. The measure is endogenous, Oppenheimer maintains, because "men in a more favorable economic position are selected into marriage in the first place" (p. 469). The implication is that I should include the experience of never-married men. But never-married men are excluded from both the independent and the dependent variables; they are not at risk to divorce or separate, so their experience is not relevant to the model. Oppenheimer then argues that the separated and divorced should be included in the employment variable, because "the employed are not only more likely to be selected into the married state, they are also less likely to be selected out of it" (p. 469). This is puzzling; I excluded the separated and divorced from the independent variable precisely to avoid this endogeneity problem. As the equation is currently set up, the only way that the dependent variable could affect the percentage of married men employed would be if divorced men were systematically discriminated against in the labor market and thus lost jobs because they were divorced, which then increased job opportunities for married men. Although this convoluted scenario may be a theoretical possibility, the effect on married men's employment would necessarily be trivial. It seems far more likely that the causal direction works the other way around: Divorce no doubt often occurs because a man is unemployed. As long as that is the direc- tion of causality, there is no potential for the dependent variable to influence the independent variable and no potential for endogeneity.

The economic measures for females are also endogenous, Oppenheimer argues, because divorced and separated women are likely to move to places where they can find work. This possibility was my greatest concern when I began this analysis, but when I found that opportunity and participation for women predicted divorce and separation for men just as well as they predicted divorce and separation for women, I realized that female labor migration could not be driving the results. The state-level analyses described in my paper (footnote 4) confirmed that the effects of women's participation and opportunity on divorce and separation were actually weaker for migrants than for nonmigrants. To the extent that migration of separated and divorced women biases the results, it probably understates the effects of opportunity for women: Separated and divorced women often moved back with their parents, and the older generation was more likely to reside in rural districts with poor opportunities for women.

Oppenheimer argues that only longitudinal data are appropriate for this kind of analysis. With a longitudinal sample, the impact of wives' employment experience on the probability of divorce or separation could be directly measured. As Oppenheimer points out, not all of the longitudinal studies carried out to date have found an unambiguous individual-level association between the work experience of wives and marital instability. ${ }^{5}$ But the economic-opportunity hypothesis does not necessarily operate at the level of individual work experience. Rather, the ability of women to escape bad marriages may be influenced less by their own employment history than by their opportunity to work. Thus, the cross-sectional contextual variables describing the local labor market for women are actually more theoretically relevant than are individual-level employment histories.

Oppenheimer is correct that there is a potential chronological mismatch between the occupation measures and marital disruptions. I assume that over the short run the occupation measures for each labor market remain reasonably stable. For example, if the participation of married white women was relatively low in rural Alabama in 1910, I assume that it was also relatively low in 1907 or 1903 . To the extent that this assumption is violated, the results would be blurred. There is no reason to suspect that short-run changes in local economic opportunities would be systematically related to the prevalence of divorce and separation. More likely, such fluctuations behave like random measurement error. Therefore, the coefficients I report are probably slightly understated because of this data limitation and should be regarded as conservative estimates.

5. Most of the studies that report insignificant effects of wives' employment on divorce and separation are recent. Perhaps, as Tzeng and Mare (1995) suggest, the direct impact of such work experience has diminished during the past few years as married women's employment has become the norm. 
In addition to these issues, both Preston and Oppenheimer point out other limitations of my independent variables. For example, I cannot control for variation in the frequency of part-time employment or the attractiveness of jobs; I cannot control for earnings changes within occupations; I do not include measures of educational attainment. The newly available Integrated Public Use Microdata Series is a powerful tool, but it can only include information that was collected by the census. The important point is that despite the simplicity of my measures, they work remarkably well. These are not subtle relationships that can be detected only with the most precise and sensitive measures of job opportunity and employment; they are big, powerful relationships, the models are highly robust, and the results are essentially the same regardless of the measures used.

\section{CONCLUSION}

The available historical data are not ideally suited to the analysis of the long-term relationship between labor markets and marital instability. Oppenheimer concludes that the data are so bad that such analyses should not even be attempted. I disagree. Much sociological theory consists of generalizations about long-term change, and far too little of it has been empirically tested. If we want to investigate long-term social change, we have to use old data. That inevitably means making compromises. All empirical scientific inquiry into the past-from geology to paleontology to historical demography-suffers from more or less incomplete data. That does not mean we abandon the effort; instead, we must be creative and flexible as we search for methods to squeeze as much as possible from the evidence that survives.

Separation and divorce were closely associated with high market participation for females, low participation for men, low opportunity for men, and high nonfarm employment for over a century. It is not plausible that these powerful and consistent relationships are the result of inadequate data. In general, measurement errors should lead to underestimated coefficients, not overestimated coefficients.

As Preston points out, a strong association between labor-market characteristics and marital instability since the late nineteenth century is not surprising. As he stresses, this association does not tell us much about the causal path. The rise of married women's participation was closely connected to the rise of separation and divorce, but that may be simply because both were part of the same larger social transformation, not because women's participation directly caused marital instability.

Finally, I concur with Preston that the most intriguing result concerns the predicted race differences in divorce and separation. Preston was coauthor of a recent paper (Morgan et al. 1994) that challenged the historical consensus that black family structure resembled white family structure until recently. I was persuaded by their argument that the large race differences in family structure apparent from the early twentieth century probably had roots in cultural differences between blacks and whites, and I echoed that interpretation in my own study of historical race differences in family structure (Ruggles 1994). The present analysis gives me second thoughts. The historical race differences in family structure are indeed dramatic, but so are the historical race differences in employment patterns. The extremely high marital instability among blacks after the Civil War may be mainly a consequence of their distinctive economic position.

\section{REFERENCES}

Becker, G.S. 1981. A Treatise on the Family. Cambridge: Harvard University Press.

Morgan, S.P., A. McDaniel, A.T. Miller, and S.H. Preston. 1993. "Racial Differences in Household Structure at the Turn of the Century." American Journal of Sociology 98:798-828.

Oppenheimer, V.O. 1994. "Women's Rising Employment and the Future of the Family in Industrial Societies." Population and Development Review 20:293-342.

Ruggles, S. 1987. Prolonged Connections: The Rise of the Extended Family in Nineteenth Century England and America. Madison, WI: University of Wisconsin Press.

Ruggles, S. 1994. "The Origins of African-American Family Structure." American Sociological Review 59:136-51.

Tzeng, J.M. and R.D. Mare. 1995. "Labor Market and Socioeconomic Effects on Marital Stability." Social Science Research 24:329-51. 